\title{
Evaluation of temperature-pulse centile charts in identifying serious bacterial illness: observational cohort study
}

\author{
Andrew J Brent, 1,2 Monica Lakhanpaul,1,3 Nelly Ninis, 1,2 Michael Levin,1,2 Roddy \\ MacFaul, 1,4 Matthew Thompson 1,5,6
}

${ }^{1}$ Royal College of Paediatrics \& Child Health (RCPCH) Working Group on Recognising Acute Illness in Children, London, UK ${ }^{2}$ Department of Paediatrics, Imperial College London, London, UK

${ }^{3}$ Division of Paediatrics, Department of Medical Education and Social Care, University of Leicester ${ }^{4}$ Paediatric Department Pinderfields Hospital,

Wakefield, UK

${ }^{5}$ Oxford University Department of Primary Health Care, Institute of Health Sciences, Oxford, UK

${ }^{6}$ Oregon Health \& Science University, Portland, Oregon, USA

\section{Correspondence to} Dr Andrew J Brent, KEMRIWellcome Trust Research Programme, PO Box 230, 80108 Kilifi, Kenya; dr.a.brent@gmail.com

Accepted 21 November 2010 Published Online First 12 January 2011

\section{ABSTRACT}

Background Distinguishing serious bacterial infection (SBI) from milder/self-limiting infections is often difficult. Interpretation of vital signs is confounded by the effect of temperature on pulse and respiratory rate. Temperature-pulse centile charts have been proposed to improve the predictive value of pulse rate in the clinical assessment of children with suspected SBI.

Objectives To assess the utility of proposed temperature-pulse centile charts in the clinical assessment of children with suspected SBI.

Study design and participants The predictive value for SBI of temperature-pulse centile categories, pulse centile categories and Advanced Paediatric Life Support (APLS) defined tachycardia were compared among 1360 children aged 3 months to 10 years presenting with suspected infection to a hospital emergency department (ED) in England; and among 325 children who presented to hospitals in the UK with meningococcal disease.

\section{Main outcome measure SBI.}

Results Among children presenting to the ED, 55 (4.0\%) had SBI. Pulse centile category, but not temperature-pulse centile category, was strongly associated with risk of $\mathrm{SBI}$ ( $p=0.0005$ and 0.288 , respectively). APLS defined tachycardia was also strongly associated with SBI (OR 2.90 (95\% Cl 1.60 to 5.26), $p=0.0002$ ). Among children with meningococcal disease, higher pulse and temperature-pulse centile categories were both associated with more severe disease $(p=0.004$ and 0.041 , respectively).

Conclusions Increased pulse rate is an important predictor of SBI, supporting National Institute for Health and Clinical Excellence recommendations that pulse rate be routinely measured in the assessment of febrile children. Temperature-pulse centile charts performed more poorly than pulse alone in this study. Further studies are required to evaluate their utility in monitoring the clinical progress of sick children over time.

\section{INTRODUCTION}

Despite great progress in the prevention of childhood infections, particularly through immunisation, infection remains a leading cause of illness and death among children in industrialised as well as developing countries. ${ }^{1}$ In the UK, a recent confidential enquiry into child deaths found that infection was the single largest natural cause of death in children. ${ }^{2}$ Although early recognition of sepsis is associated with better treatment outcomes, ${ }^{3} 4$ this and other reports have highlighted the difficulty often faced by clinicians in recognising serious illness in children, partly because many

\section{What is already known on this topic}

- Distinguishing serious bacterial infection (SBI) from milder/self-limiting infections is often difficult but is important to avoid serious illness and death.

- Debate exists regarding the utility of pulse rate in the assessment of children with suspected infection, since fever itself causes tachycardia.

\section{What this study adds}

- There was strong evidence for an association between increased pulse rate/tachycardia and risk of SBI.

- Temperature-pulse centile charts performed more poorly than pulse alone in identifying children with SBI in this study.

- These data support National Institute of Health and Clinical Excellence.

of the early clinical features of serious bacterial infection (SBI) also occur in milder, self-limiting febrile illnesses. ${ }^{2} 56$

The need for simple tools to help guide clinical decision-making is most acute in the settings of primary care and hospital emergency departments (EDs), where only a small proportion of the large presenting case load has a serious acute medical condition, ${ }^{7}$ but where failure to identify these children may be life-threatening. Given limited time and diagnostic resources to perform detailed investigations on all children, assessment relies in most cases on history and clinical examination. Vital signs have an important role in indicating a child's current physiological state. ${ }^{6}{ }^{8}$ However, interpretation is often difficult in febrile children, since fever itself elevates both pulse and respiratory rates. Perhaps reflecting this, a recent study of general practitioners in the UK revealed that many doubt the utility of measuring the pulse rate in febrile children. ${ }^{9}$

In an attempt to control for the confounding effect of temperature on the relationship between pulse rate and serious (usually bacterial) infections, age-specific temperature-pulse centile charts derived from children with self-limiting febrile illnesses have been proposed. ${ }^{10}$ These centile charts represent a novel and potentially very useful tool to aid clinicians working in front 
line health services. In order to determine the clinical utility of these centile charts in identifying children with SBIs, we tested their performance in two separate paediatric populations presenting to hospital in the UK.

\section{METHODS}

\section{Participants and clinical definitions}

Data for analysis were derived from two studies. The first was a study of paediatric presentations to a hospital ED; the second a large national case control study of factors associated with death and survival from meningococcal disease. Data-collection methods and clinical definitions for both studies have been described in detail elsewhere (A J Brent, M Lakhanpaul, M Thompson, et al (published online Arch Dis Child 2011.183111), unpublished observations). ${ }^{11}$

For the ED study, data on presenting clinical symptoms and signs, laboratory indices, treatment and final diagnosis were collected prospectively on all children presenting to a large ED in Nottingham, with the exception of children requiring emergency resuscitation directly at presentation (A J Brent, M Lakhanpaul, M Thompson, et al (published online Arch Dis Child 2011.183111), unpublished observation). Each child's outcome was classified as SBI or not SBI after a detailed review of clinical and laboratory data. SBI was defined as admission to hospital plus any of the following (in the absence of an alternative non-infective or non-bacterial diagnosis to explain the clinical and laboratory findings): positive bacterial cultures from blood or another normally sterile site in the appropriate clinical context; radiological signs of pneumonia; clinical meningitis plus a cerebrospinal fluid polymorphonuclear leucocytosis; acute febrile purpura; deep collection(s) requiring intravenous antibiotics \pm surgical drainage; a white blood cell count $\geq 20 \times 10^{9} / 1$; a C reactive protein $\geq 120 \mathrm{mg} / 1$; or a final diagnosis of septic arthritis, osteomyelitis, empyema or mastoiditis. Children who reattended hospital within 1 week of discharge from either the ED or the ward were identified from the electronic patient register, their notes reviewed, and final diagnoses and SBI classification amended in the light of their second presentation (A J Brent, M Lakhanpaul, M Thompson, et al (published online Arch Dis Child 2011.183111), unpublished observation).

For the meningococcal study, regional notification data and data from the Office for National Statistics were used to identify incident cases of paediatric meningococcal disease between December 1997 and February 1999 (A J Brent, M Lakhanpaul, M Thompson, et al (published online Arch Dis Child 2011.183111), unpublished observation). ${ }^{5}$ Each case was classified according to accepted definitions as possible, probable or confirmed meningococcal disease, ${ }^{12}$ and any unconfirmed cases were excluded following expert panel review. For each fatal case, three ageand region-matched survivors were selected, and clinical data at hospital presentation were extracted retrospectively from the case notes of children. Severe meningococcal disease was defined a priori as a Glasgow Meningococcal Septicaemia Prognostic Score $>8.1314$

For each dataset, we confined this analysis to children aged between 3 months and 10 years, since these are the age groups for which centile charts have been proposed, ${ }^{10}$ and to those for whom a contemporaneous temperature and pulse were documented at presentation. We also confined analysis of the meningococcal dataset to children with meningococcal septicaemia, and excluded children with meningitis and signs of raised intracranial pressure to avoid possible confounding due to bradycardia caused by raised intracranial pressure. Tachycardia was defined according to UK Advanced Paediatric Life Support (APLS) guidelines as a heart rate $>160$ beats $/ \mathrm{min}$ in children $<1$ year old; $>150$ beats/min in children $1-2$ years old; $>140$ beats/min in children $3-4$ years old; and $>120$ beats/ min in children $5-12$ years old. ${ }^{15}$

\section{Statistical methods}

For each dataset, we summarised demographic and outcome data for children included in this analysis. Temperature-pulse centile categories were defined according to the published agespecific temperature-pulse centile charts. ${ }^{10}$ For comparison, corresponding age group-specific centile categories for pulse rate alone (irrespective of temperature) were derived among all children in the ED dataset.

To investigate the performance of the centile charts in the clinical assessment of children presenting to the ED with possible SBI, we plotted each child's admission temperature and pulse on the appropriate age-specific centile chart. We calculated the OR for SBI in each centile range, and performed a $\chi^{2}$ test for trend in the proportion of children with SBI across temperature-pulse centile categories. For comparison, we also calculated the OR for SBI in each pulse centile range and performed a $\chi^{2}$ test for trend across pulse centile ranges. We then calculated the sensitivity, specificity, positive predictive value (PPV) and negative predictive value (NPV) and positive likelihood ratio $(\mathrm{LR}+)$ and negative likelihood ratio $(\mathrm{LR}-)$ of cutoffs defined by temperature-pulse centiles, pulse centiles and tachycardia alone for identifying children with SBI.

To investigate the utility of the temperature-pulse centile charts in identifying children with meningococcal septicaemia, we plotted these children's temperature and pulse, and performed $\chi^{2}$ tests for trend in the proportion of children who had severe meningococcal disease (GSMP score >8) across centile categories. The sensitivity for SBI of cut-offs defined by temperature-pulse centiles, pulse centiles and tachycardia alone was calculated overall and for those with severe disease at presentation.

All analyses were performed using Stata version 10 (Stata).

\section{Research ethics approval}

Research ethics approval for the ED and meningococcal studies was granted by the Nottingham Research Ethics Committee and the South Thames Multi-Research Ethics Committee, respectively. The current analysis was also approved by the research ethics committee of the London School of Hygiene and Tropical Medicine.

\section{RESULTS}

The final ED dataset comprised 1360 children with a median age of 21 months (IQR 9-47 months), of whom 786 (57.9\%) were boys, and $55(4.0 \%)$ had SBI. Final diagnoses of children with SBI included pneumonia (41), sepsis without a clear focus (10), urinary sepsis (2) and soft-tissue infection (2). One hundred and thirty-three $(9.8 \%)$ children could not be assigned a temperature-pulse category, since their temperature lay outside the range for which age-specific centiles have been defined. The proportion of children with SBI in this group (four children, $3.0 \%$ ) was not significantly different from those whose temperature lay within the ranges of the centile charts $(p=0.523)$.

Scatter graphs of temperature and pulse for children presenting to the ED with and without SBI are shown superimposed on the age-specific temperature-pulse centile charts in 

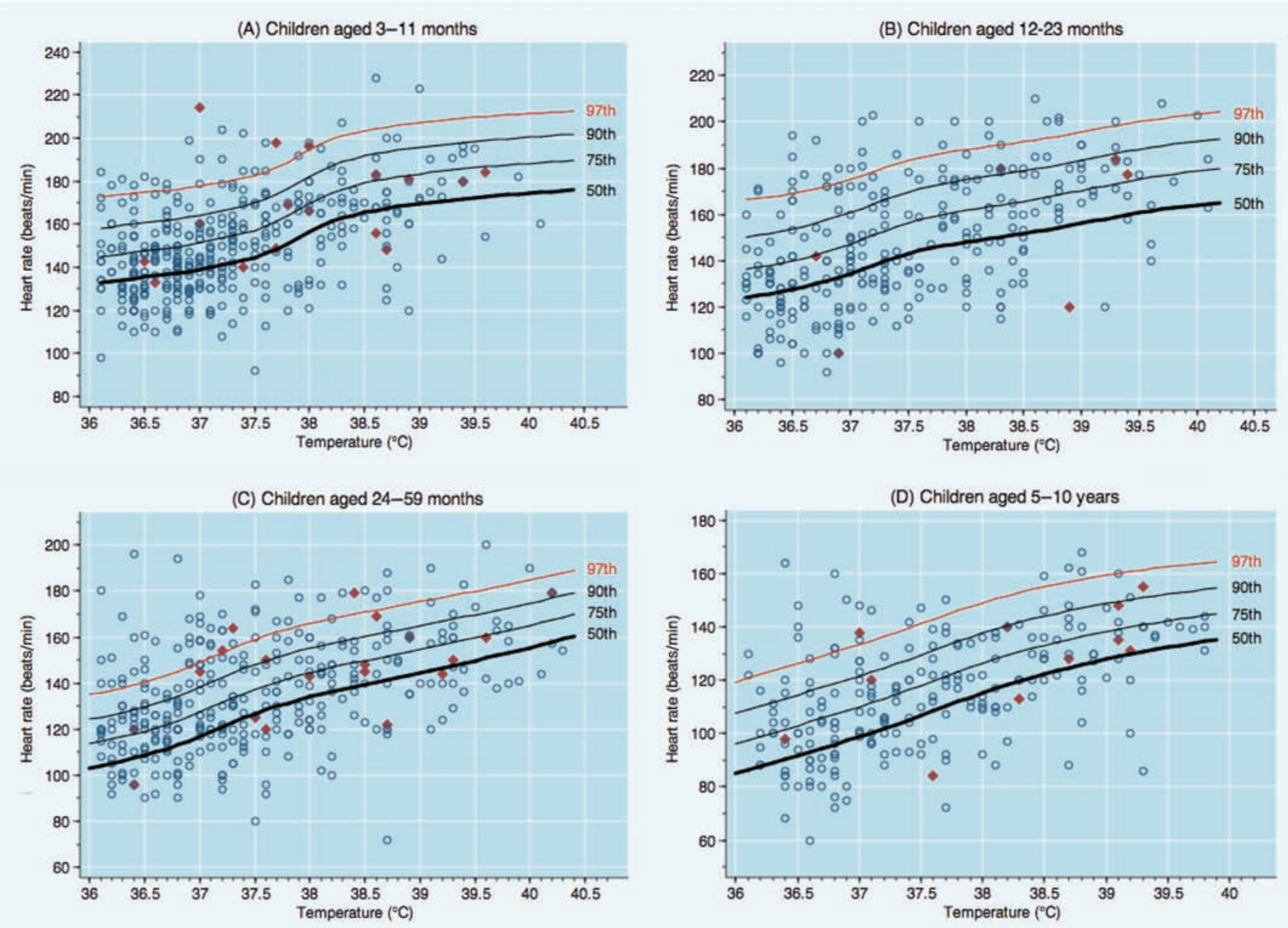

- Significant bacterial infection

- Not significant bacterial infection

Figure 1 Temperature and pulse of children presenting to the emergency department with and without significant bacterial infection, superimposed on age-specific temperature-pulse centile charts.

Table 1 Distribution of temperature-pulse data by centile group for children presenting to the emergency department with suspected serious bacterial infection

\begin{tabular}{|c|c|c|c|c|c|}
\hline Nomogram centile category & $\mathbf{N}$ & $\begin{array}{l}\text { Children with serious } \\
\text { bacterial infection ( } n \text { ) }\end{array}$ & $\mathbf{O R}$ & $95 \% \mathrm{Cl}$ & p Value \\
\hline \multicolumn{6}{|c|}{ Age specific temperature-pulse centiles } \\
\hline$>97$ th centile & 132 & 7 & 1.84 & 0.72 to 4.71 & \multirow[t]{4}{*}{0.288} \\
\hline$>75$ th-90th centile & 227 & 11 & 1.67 & 0.73 to 3.79 & \\
\hline$>50$ th-75th centile & 316 & 16 & 1.75 & 0.83 to 3.69 & \\
\hline$\leq 50$ th centile & 439 & 13 & 1.00 & - & \\
\hline$>97$ th centile & 28 & 1 & 1.51 & 0.19 to 12.0 & \multirow[t]{5}{*}{0.0005} \\
\hline 90th-97th centile & 91 & 10 & 5.04 & 2.14 to 11.9 & \\
\hline 75th-90th centile & 199 & 12 & 2.62 & 1.19 to 5.79 & \\
\hline 50th-75th centile & 324 & 14 & 1.85 & 0.87 to 3.93 & \\
\hline$<50$ th centile & 586 & 14 & 1.00 & - & \\
\hline Tachycardia & 514 & 34 & 2.90 & 1.60 to 5.26 & 0.0002 \\
\hline
\end{tabular}

figure 1. The distribution of children with and without SBI and ORs for SBI by temperature-pulse centile ranges, pulse centile ranges and tachycardia are shown in table 1 . There was no significant trend across temperature-pulse centile categories in the proportion of children with SBI $(p=0.288)$; however the risk of SBI increased significantly with higher pulse centile ranges ( $p=0.0005$; table 1$)$. This is reflected in the poorer diagnostic performance for SBI of cut-offs defined by temperature-pulse centiles compared with pulse centiles and tachycardia (table 2). As expected, specificity increased for higher 
Table 2 Sensitivity, specificity, $\mathrm{PPVs}^{*}$ and $\mathrm{NPVs}^{\dagger}$ for significant bacterial infection of cut-offs defined by temperature-pulse and pulse centiles and by tachycardia

\begin{tabular}{|c|c|c|c|c|c|c|}
\hline & $\begin{array}{l}\text { Percentage sensitivity } \\
(95 \% \mathrm{CI})\end{array}$ & $\begin{array}{l}\text { Percentage specificity } \\
(95 \% \mathrm{CI})\end{array}$ & $\begin{array}{l}\text { Percentage PPV } \\
(95 \% \mathrm{CI})\end{array}$ & $\begin{array}{l}\text { Percentage NPV }{ }^{\dagger} \\
(95 \% \mathrm{CI})\end{array}$ & $\begin{array}{l}\text { Percentage } \text { LR }^{+\ddagger} \\
(95 \% \mathrm{CI})\end{array}$ & $\begin{array}{l}\text { Percentage } \text { LR }^{-\S} \\
(95 \% \mathrm{CI})\end{array}$ \\
\hline \multicolumn{7}{|c|}{ Age-specific temperature-pulse centiles } \\
\hline Above 97 th centile & 13.7 (5.7 to 26.3$)$ & $89.4(87.5$ to 91.1$)$ & $5.3(2.2$ to 10.6$)$ & $96.0(94.6$ to 97.1$)$ & $1.4(0.69$ to 2.7$)$ & $0.96(0.48$ to 1.9$)$ \\
\hline Above 90th centile & 21.6 (11.3 to 35.3$)$ & $80.0(77.6$ to 82.3$)$ & $4.5(2.3$ to 7.9$)$ & 95.9 (94.5 to 97.1$)$ & $1.2(0.76$ to 1.8$)$ & $0.96(0.63$ to 1.5$)$ \\
\hline Above 75 th centile & $43.1(29.3$ to 57.8$)$ & $61.7(58.8$ to 64.5$)$ & $4.7(2.9$ to 7.0$)$ & $96.2(94.5$ to 97.4$)$ & $1.2(0.58$ to 2.3$)$ & $0.90(0.45$ to 1.8$)$ \\
\hline Above 50th centile & 74.5 (60.4 to 85.7$)$ & 36.2 (33.4 to 39.0$)$ & $4.8(3.4$ to 6.6$)$ & $97.0(95.0$ to 98.4$)$ & $1.1(0.50$ to 2.6$)$ & $0.75(0.33$ to 1.7$)$ \\
\hline \multicolumn{7}{|c|}{ Age-specific pulse centiles } \\
\hline Above 97th centile & $2.0(0.04$ to 10.4$)$ & 97.7 (96.7 to 98.5$)$ & $3.6(0.1$ to 18.3$)$ & 95.8 (94.5 to 96.9$)$ & $2.7(2.2$ to 3.4$)$ & $0.96(0.76$ to 1.2$)$ \\
\hline Above 90th centile & 21.6 (11.3 to 35.3$)$ & $90.8(89.0$ to 92.4$)$ & $9.2(4.7$ to 15.9$)$ & $96.4(95.1$ to 97.4$)$ & $2.4(1.6$ to 3.7$)$ & $0.86(0.57$ to 1.3$)$ \\
\hline Above 75th centile & 45.1 (31.1 to 59.7$)$ & 75.7 (73.1 to 78.1$)$ & 7.2 (4.6 to 10.7$)$ & 96.9 (95.6 to 97.9$)$ & $1.7(0.84$ to 3.3$)$ & $0.78(0.40$ to 1.5$)$ \\
\hline Above 50th centile & 72.5 (58.3 to 84.1$)$ & $48.6(45.7$ to 51.5$)$ & $5.8(4.1$ to 7.9$)$ & $97.6(96.0$ to 98.7$)$ & $1.3(0.58$ to 3.1$)$ & $0.64(0.28$ to 1.5$)$ \\
\hline Tachycardia & 66.7 (52.1 to 79.2$)$ & 59.2 (56.3 to 62.0$)$ & 6.6 (4.6 to 9.1 ) & 97.6 (96.2 to 98.6$)$ & 1.5 (0.67 to 3.4$)$ & $0.65(0.29$ to 1.46$)$ \\
\hline
\end{tabular}

*PPV, positive predictive value (predictive value of a positive test).

${ }^{\dagger} \mathrm{NPV}$, negative predictive value (predictive value of a negative test).

${ }^{\ddagger} \mathrm{LR}+$, likelihood ratio of a positive test.

${ }^{\S} \mathrm{LR}-$, likelihood ratio of a negative test.

temperature-pulse and pulse centiles, but at the expense of very poor sensitivity. There was strong evidence of an association between tachycardia and SBI (OR 2.90 (95\% CI 1.60 to 5.26), $\mathrm{p}=0.0002$ ).

In the meningococcal dataset, admission temperature and pulse data were available for 325 children with a median age of 23 months (IQR 9-50 months), of whom 86 (31.3\%) had severe disease on admission. The admission temperature of 19 (5.8\%) children lay outside the range for which age-specific centiles have been defined; there was no difference in the proportion with severe disease between these children and those whose temperature lay within the centile chart ranges $(p=0.115)$. Scatter graphs of admission temperature and pulse for children with and without severe disease are shown superimposed on temperature-pulse centile charts in figure 2. Higher temperature-pulse centile categories and higher pulse centile categories were both associated with a higher proportion of children with severe disease ( $p=0.041$ and $p=0.004$, respectively). The sensitivity of cut-offs defined by temperature-pulse centiles, pulse centiles and tachycardia alone are shown in table 3.

\section{DISCUSSION}

Distinguishing children with serious infections from those with milder, self-limiting febrile illnesses remains a daily challenge in primary care and hospital EDs, where clinicians rely on a limited number of clinical symptoms and signs to risk-stratify children for further observation, investigation and/or referral. ${ }^{6}$ Measurement of vital signs is recommended as part of this assessment, but evidence for the predictive value of individual or combinations of vital signs in these settings is limited. ${ }^{6}$ Centile charts such as those published by Thompson et a ${ }^{10}$ might make an important contribution to the assessment of febrile children if they could be shown to improve the predictive value of heart rate as one component of this assessment.

The performance of the temperature-pulse centile charts in this study was disappointing. There was no strong evidence of an association between temperature-pulse centile category and risk of SBI, reflected in the poor sensitivity, specificity, PPVs, NPVs, LR+ and LR- of individual centile cut-offs. Importantly, although imperfect, the corresponding age group-specific centile ranges for pulse alone was more strongly associated with SBI, and the simpler APLS definition of tachycardia was a better predictor of SBI. This is perhaps not surprising, since bacterial infection causes fever, which in turn increases the pulse rate, so that increased temperature positively confounds (is at least part of the explanation for) the observed association between increased pulse rate and SBI. One would therefore expect any adjustment for the effect of temperature (eg, using the temperature-pulse centiles) to reduce the strength of this association.

Owing to the relatively small proportion of children with $\mathrm{SBI}$ in the ED dataset we also examined the performance of the centile charts in identifying children with meningococcal septicaemia in a large, independent dataset. The sensitivity for meningococcal septicaemia of cut-offs defined by each temperature-pulse centile was nevertheless disappointing. Since meningococcal disease represents a broad clinical spectrum, and children may present at different stages of their illness, we further explored the value of the centile charts in identifying those children with severe disease at presentation. However, the sensitivity of temperature-pulse centile cut-offs for identifying this group remained poor, and in both groups tachycardia alone was a more sensitive predictor of meningococcal septicaemia.

The strengths of the ED dataset include the large number of children for whom detailed clinical and laboratory data were collected prospectively, and the non-selective nature of the group of children included, which suggests our findings might be generalisable to other paediatric ED settings. One potential limitation is the lack of a clear, gold-standard definition of severe bacterial illness. Definitions confined to microbiologically confirmed invasive bacterial disease (such as a positive blood culture) are highly specific but lack sensitivity, since a microbiological diagnosis is achieved in only a minority of cases. ${ }^{16-18}$ Adopting such a definition would not only reduce the power of any analysis of potential clinical predictors, but also limit the generalisability of the findings, since clinical features of children with microbiologically confirmed bacterial disease may differ from those in whom microbiological confirmation is not possible. We therefore adopted a pragmatic but nevertheless rigorous definition of SBI that sought to capture the full range of children requiring admission and/or treatment for proven or presumed severe bacterial infections.

The main limitation of the meningococcal dataset is the inclusion of only children with meningococcal disease, so we were unable to assess the specificity, NPV or PPV of centile cutoffs in indentifying children presenting with meningococcal 

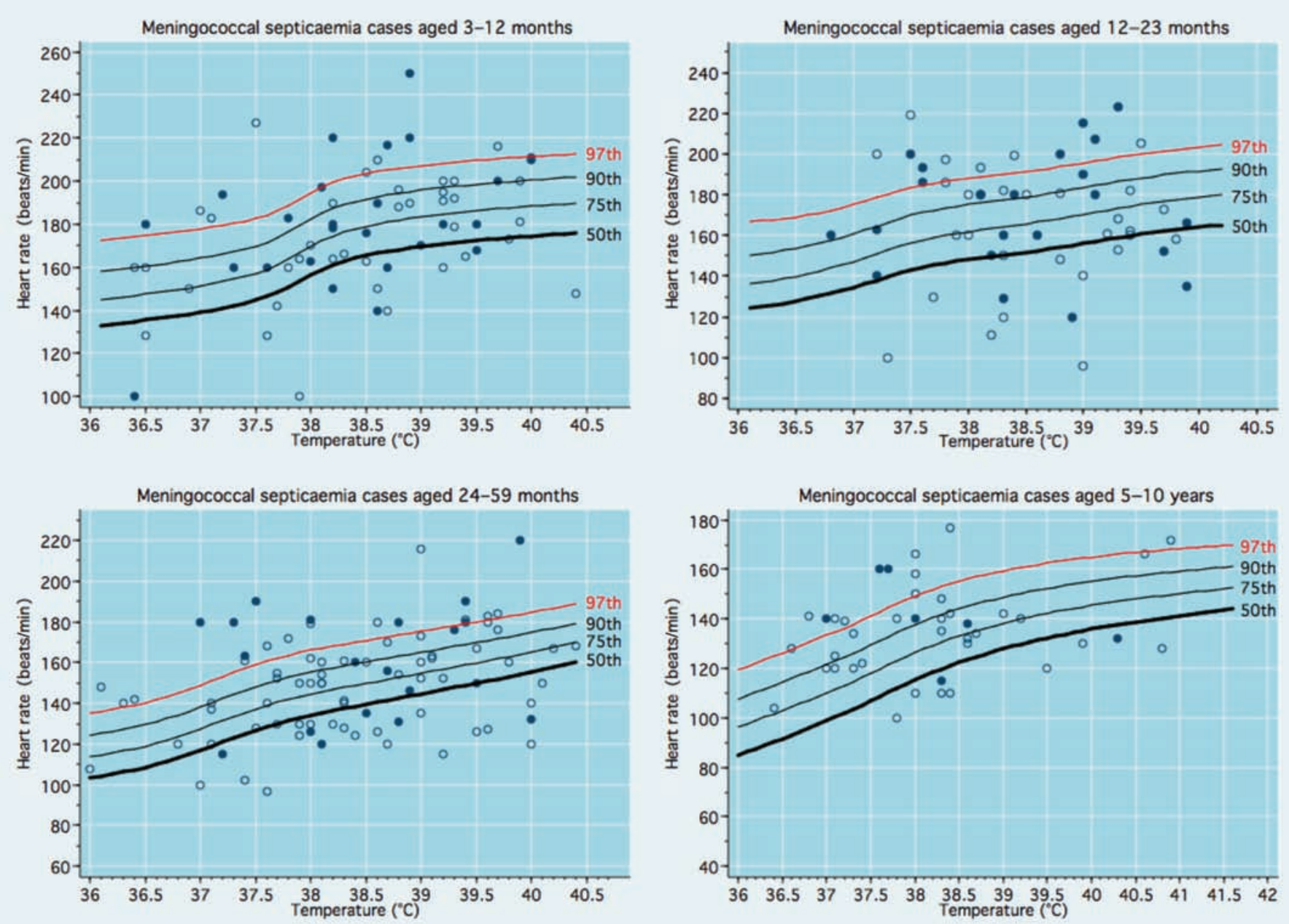

\section{- Admission GMSP score $>8$ \\ - Admission GMSP score $<8$}

Figure 2 Admission temperature and pulse of children with meningococcal septicaemia, superimposed on proposed age-specific temperaturepulse centile charts. GMSP, Glasgow Meningococcal Septicaemia Prognostic score.

Table 3 Sensitivity of cut-offs defined by temperature-pulse centiles, pulse centile and tachycardia for detecting children with meningococcal septicaemia of various degrees of severity

\begin{tabular}{l}
$\begin{array}{l}\text { Percentage sensitivity of centile ranges for } \\
\text { identifying all children with meningococcal } \\
\text { septicaemia and those with severe disease } \\
(95 \% \mathrm{Cl})\end{array}$ \\
\hline $\begin{array}{l}\text { All children with } \\
\text { meningococcal } \\
\text { septicaemia }\end{array}$
\end{tabular}

Age-specific temperature-pulse centiles

$\begin{array}{lll}\text { Above } 97 \text { th centile } & 23.6(18.5 \text { to } 29.3) & 33.3(22.9 \text { to } 45.2) \\ \text { Above 90th centile } & 37.8(31.8 \text { to } 44.1) & 50.7(38.9 \text { to } 62.4) \\ \text { Above } 75 \text { th centile } & 55.5(49.2 \text { to } 61.7) & 62.7(50.7 \text { to } 73.6) \\ \text { Above 50th centile } & 70.1(64.0 \text { to } 75.6) & 74.7(63.3 \text { to } 84.0) \\ \text { Below 50th centile } & 29.9(24.4 \text { to } 36.0) & 25.3(16.0 \text { to } 36.7) \\ \text { age-specific pulse centiles } & & \\ \text { Above 97th centile } & 11.0(7.7 \text { to } 15.1) & 17.9(10.2 \text { to } 28.3) \\ \text { Above 90th centile } & 27.8(22.8 \text { to } 33.2) & 38.5(27.7 \text { to } 50.2) \\ \text { Above } 75 \text { th centile } & 49.2(43.4 \text { to } 55.0) & 61.5(49.8 \text { to } 72.3) \\ \text { Above 50th centile } & 73.9(68.5 \text { to } 78.8) & 84.6(74.7 \text { to } 91.8) \\ \text { Below 50th centile } & 26.1(21.2 \text { to } 31.5) & 15.4(8.2 \text { to } 25.3) \\ \text { Tachycardia } & 68.9(63.3 \text { to } 74.1) & 78.2(67.4 \text { to } 86.8)\end{array}$

disease. The case-control design of the original meningococcal study also results in over-representation of fatal cases. ${ }^{11}$ Given the observed association between higher pulse rate and severe disease, this is likely to have resulted in a slight overestimate of the sensitivity for SBI of all three methods of pulse assessment (temperature-pulse centiles, pulse centiles and APLS definition of tachycardia).

Measurement error is also possible in both datasets, since temperature and pulse rate were measured in the routine clinical setting. This is likely to be minimal in the ED dataset, since temperature and pulse rate were measured using an electronic tympanic thermometer and pulse oximeter. However, methods of vital sign measurement are not documented for children in the meningococcal dataset (who presented to many different hospitals), and there was no standardised mechanism for calibration of the instruments in either study. Nevertheless, this pragmatism may be a strength of our study, increasing its generalisability to other routine clinical settings.

Although the findings of this study do not appear to support a role for the temperature-pulse centile charts in identifying children with SBI at presentation, it is important to assess their utility in a variety of clinical settings. A recent study in a paediatric ED did show an association between 
higher temperature-pulse centiles and serious infection. ${ }^{19}$ The higher PPV of a pulse above the 90th temperature-pulse centile observed in this study $(23 \%)$ may reflect a broader definition of serious infection. No comparison was made with pulse centiles alone. To date, no study has assessed the performance of the centile charts in a primary care setting where the prevalence of serious infection is lower.

Importantly, despite the disappointing performance of the temperature-pulse centile charts, these data do confirm a significant association between pulse rate alone and SBI among children presenting to the ED, supporting recommendations from the UK National Institute for Health and Clinical Excellence that vital signs including the pulse rate be measured in the assessment of all febrile children. ${ }^{6}$ Formal demonstration of a direct clinical benefit arising from routine measurement of the pulse is challenging, owing to multiple potential biases and confounders, perhaps explaining why data addressing this question are scarce. ${ }^{6}$ Nevertheless, given these methodological challenges, and pending evidence to the contrary, we believe that pulse rate should remain a routine part of the assessment of a febrile child, since it is quick and easy to elicit, helps to provide a more complete picture of the child's physiological state and facilitates monitoring of their clinical course. Clinical guidelines stress the importance of reviewing a child's clinical progression, particularly if symptoms do not resolve, ${ }^{2} 68$ and changes in a child's physiological state may be at least as informative as their condition at a single time point. ${ }^{8}$ The role of the temperature-pulse centile charts may be in controlling for the confounding effects of temperature on pulse in assessing the clinical progression of an individual child, rather than at a single presentation. This hypothesis requires further investigation in longitudinal studies.

Acknowledgements The study was carried out on behalf of the Royal College of Paediatrics \& Child Health (RCPCH) working group on Recognising Acute Illness in Children (RAIC). MT is a member of University of Oxford Department of Primary Health Care that is part of the NIHR National School of Primary Care Research. $\mathrm{ML}$ is member of the Leicester Collaboration for Leadership in Applied Health Research and Care (CLARCH) team and Director of the Health Education Research and Development Unit (HERADU). The authors would like to thank S Ray, J Collier and T Stephenson for their contributions to the initial data collection and analysis; and staff and patients at the Nottingham Queens Medical Centre emergency department for their help and participation in the study.

Funding AJB is supported by a Wellcome Trust research training fellowship (081697). The authors wish to thank the Meningitis Research Foundation for their support for the meningococcal study, and the Well Child Medical Charity for their funding of the studies in Nottingham and for this study. Funding for the University of Oxford Department of Primary Health Care work on vital signs is provided by the NIHR programme grant 'Development and implementation of new diagnostic processes and technologies in primary care.'

Competing interests None.
Ethics approval Ethics approval was provided by the emergency department and meningococcal studies — granted by the Nottingham Research Ethics Committee and the South Thames Multi-Research Ethics Committee, respectively. The current analysis was also approved by the ethics committee of the London School of Hygiene and Tropical Medicine.

Provenance and peer review Not commissioned; externally peer reviewed.

\section{REFERENCES}

1. Bryce J, Boschi-Pinto C, Shibuya K, et al. WHO estimates of the causes of death in children. Lancet 2005:365:1147-52.

2. Pearson GA. Why Children Die: A Pilot Study 2006, England (South West, North East and West Midlands), Wales and Northern Ireland. London: Confidential Enquiry into Maternal and Child Health 2008.

3. Dellinger RP, Levy MM, Carlet JM, et al. Surviving Sepsis Campaign: international guidelines for management of severe sepsis and septic shock: 2008 Crit Care Med 2008;36:296-327.

4. Kumar A, Roberts D, Wood KE, et al. Duration of hypotension before initiation of effective antimicrobial therapy is the critical determinant of survival in human septic shock. Crit Care Med 2006;34:1589-96.

5. Thompson MJ, Ninis N, Perera R, et al. Clinical recognition of meningococcal disease in children and adolescents. Lancet 2006;367:397-403.

6. NICE. Feverish IIIness in Children: Assessment and Initial Management in Children Younger Than 5 Years. London: National Institute of Clinical Excellence, 2007.

7. MacFaul R. The Health of Children and Young People: Provision and Use of Services. Newport: Office for National Statistics, 2004.

8. Duncan H, Hutchison J, Parshuram CS. The Pediatric Early Warning System score: a severity of illness score to predict urgent medical need in hospitalized children. J Crit Care 2006;21:271-8.

9. Thompson M, Mayon-White R, Harnden A, et al. Using vital signs to assess children with acute infections: a survey of current practice. Br J Gen Pract 2008; $58: 236-41$

10. Thompson M, Harnden A, Perera R, et al. Deriving temperature and age appropriate heart rate centiles for children with acute infections. Arch Dis Child 2009;94:361-5.

11. Ninis N, Phillips C, Bailey L, et al. The role of healthcare delivery in the outcome of meningococcal disease in children: case-control study of fatal and non-fatal cases. BMJ 2005;330:1475

12. Ramsay M, Kaczmarski E, Rush M, et al. Changing patterns of case ascertainment and trends in meningococcal disease in England and Wales. Commun Dis Rep CDR Rev 1997;7:R49-54.

13. Sinclair JF, Skeoch CH, Hallworth D. Prognosis of meningococcal septicaemia. Lancet 1987;2:38.

14. Thomson AP, Sills JA, Hart CA. Validation of the Glasgow Meningococcal Septicemia Prognostic Score: a 10-year retrospective survey. Crit Care Med 1991;19:26-30.

15. Advanced Life Support Group. Advanced Paediatric Life Support: The Practical Approach. 4th edn. Wiley-Blackwell, Oxford, UK. 2004.

16. Cutts FT, Zaman SM, Enwere G, et al. Efficacy of nine-valent pneumococcal conjugate vaccine against pneumonia and invasive pneumococcal disease in The Gambia: randomised, double-blind, placebo-controlled trial. Lancet 2005; 365:1139-46

17. Luck S, Torny M, d'Agapeyeff K, et al. Estimated early-onset group B streptococcal neonatal disease. Lancet 2003;361:1953-4.

18. Sáez-Llorens X, Vargas S, Guerra F, et al. Application of new sepsis definitions to evaluate outcome of pediatric patients with severe systemic infections. Pediatr Infect Dis J 1995; 14:557-61.

19. Thompson M, Coad N, Harnden A, et al. How well do vital signs identify children with serious infections in paediatric emergency care? Arch Dis Child 2009;94:888-93 


\title{
Risk score to stratify children with suspected serious bacterial infection: observational cohort study
}

\author{
Andrew J Brent, 1,2 Monica Lakhanpaul, 1,3 Matthew Thompson,1,4,5 Jacqueline Collier,1,6 \\ Samiran Ray, ${ }^{7}$ Nelly Ninis, ${ }^{1,2}$ Michael Levin, ${ }^{1,2}$ Roddy MacFaul ${ }^{1,8}$
}

${ }^{1}$ Royal College of Paediatrics and Child Health (RCPCH) Working Group on Recognising Acute Illness in Children, London, UK

${ }^{2}$ Department of Paediatrics, Imperial College London, London, UK

${ }^{3}$ Department of Medical Education and Social Care, University of Leicester, Leicester, UK

${ }^{4}$ Oxford University Department of Primary Health Care, Institute of Health Sciences, Oxford, UK

${ }^{5}$ Department of Family Medicine, Oregon Health \& Science University, Portland, Oregon, USA

${ }^{6}$ Centre for Population Sciences, University of Nottingham, Nottingham, UK

${ }^{7}$ Paediatric Intensive Care Unit, Great Ormond Street Hospital,

London, UK

${ }^{8}$ Paediatric Department,

Pinderfields Hospital,

Wakefield, UK

\section{Correspondence to} Dr Andrew J Brent, KEMRIWellcome Trust Research Programme, P0 Box 230, 80108 Kilifi, Kenya; dr.a.brent@gmail.com

Accepted 14 December 2010 Published Online First 24 January 2011

\begin{abstract}
Objectives To derive and validate a clinical score to risk stratify children presenting with acute infection.

Study design and participants Observational cohort study of children presenting with suspected infection to an emergency department in England. Detailed data were collected prospectively on presenting clinical features, laboratory investigations and outcome. Clinical predictors of serious bacterial infection (SBI) were explored in multivariate logistic regression models using part of the dataset, each model was then validated in an independent part of the dataset, and the best model was chosen for derivation of a clinical risk score for SBI. The ability of this score to risk stratify children with $\mathrm{SBI}$ was then assessed in the entire dataset.
\end{abstract}

Main outcome measure Final diagnosis of SBI according to criteria defined by the Royal College of Paediatrics and Child Health working group on Recognising Acute Illness in Children.

Results Data from 1951 children were analysed. 74 (3.8\%) had SBI. The sensitivity of individual clinical signs was poor, although some were highly specific for SBI. A score was derived with reasonable ability to discriminate SBI (area under the receiver operator characteristics curve $0.77,95 \% \mathrm{Cl} 0.71$ to 0.83 ) and risk stratify children with suspected SBI.

Conclusions This study demonstrates the potential utility of a clinical score in risk stratifying children with suspected SBI. Further work should aim to validate the score and its impact on clinical decision making in different settings, and ideally incorporate it into a broader management algorithm including additional investigations to further stratify a child's risk.

\section{INTRODUCTION}

Serious bacterial infections (SBIs) are a leading cause of morbidity and mortality among children worldwide. A recent review of child deaths in England, Wales and Northern Ireland confirmed that the largest single cause of death in children dying of an acute physical illness was infection, and found evidence that healthcare professionals in both hospital and primary care had difficulty identifying serious illness in children. ${ }^{1}$ In another study of over 400 children with meningococcal sepsis in the UK, only half were referred to hospital at their first primary care consultation, usually after a delay of several hours following the first symptoms and/or signs of sepsis. ${ }^{2}$ Early recognition of SBIs is associated with better treatment outcomes ${ }^{3}{ }^{4}$ but is challenging as many of the early clinical features also occur in self-limiting illnesses. In developed countries, discriminating serious infection from self-limiting illness

\section{What is already known on this topic}

- Serious bacterial infections (SBI) are a leading cause of childhood illness and death in the UK and worldwide.

- In clinical practice, discriminating children with SBI from those with other self-limiting infections is challenging.

- A simple, validated clinical tool to risk stratify and guide further management of children with suspected SBI would greatly improve their care.

\section{What this study adds}

- The high specificity for SBI of some clinical signs supports their use in clinical guidelines to identify seriously ill children.

- The utility of a simple clinical score to stratify children according to SBI risk is clearly demonstrated.

- Combining this clinical tool with laboratory tests in a broader management algorithm may further improve SBI diagnosis pathways.

is further complicated by the low prevalence of serious infection in children presenting to hospital emergency departments as well as primary care settings..$^{5}$ Better clinical tools are therefore required to improve the recognition of children with serious acute illness, particularly SBIs. ${ }^{1} 67$

Clinical prediction rules utilising key clinical features to generate a diagnostic or prognostic score are increasingly used to risk stratify patients in a wide variety of clinical situations, particularly those in which diagnostic decisions are complicated, and in some areas have had a major impact on clinical service delivery. ${ }^{8-15}$ We aimed to develop a simple clinical score with the ability to risk stratify children with possible SBIs presenting to a paediatric emergency department.

\section{METHODS}

\section{Patients and setting}

As part of a large prospective study of patient care pathways, detailed clinical data were collected prospectively on all children presenting to the Queen's Medical Centre Emergency Department in Nottingham between September 2000 and March 2001, and September 2001 and March 2002, 
with the exception of neonates and children requiring immediate emergency resuscitation at presentation. A triage nurse recorded vital signs prior to assessment by emergency department clinical staff. All clinical data including investigations, management and final diagnoses were directly entered onto a standard proforma. Completed proformas were then scanned using Formic electronic data capture software to minimise data entry errors. Study clinicians checked the data for completeness, resolved data gaps and inconsistencies by re-review of the clinical notes, and recorded additional clinical data on children who were admitted. Children who re-attended hospital within 1 week of discharge from either the emergency department or the ward were identified from the electronic patient register, their notes reviewed, and final diagnoses and SBI classification amended in the light of their second presentation. A consultant paediatrician re-reviewed the patient records of all those admitted to check the accuracy of the data, particularly in relation to the final diagnosis recorded.

Children were eligible for inclusion in this analysis if their differential diagnosis at presentation included acute infection. We excluded from the analysis children for whom data were insufficient to confidently assign outcome, or who had missing dates of birth.

\section{Clinical definitions}

Automated measurements were used for temperature (tympanic thermometer), pulse rate, blood pressure and pulse oximetry. Tachypnoea, tachycardia and hypotension were defined according to UK Advanced Paediatric Life Support guidelines ${ }^{16}$; children for whom no blood pressure recordings were available were assumed not to be hypotensive for the purpose of the analysis. We adopted pragmatic definitions of mild hypoxia $\left(\mathrm{SaO}_{2}<95 \%\right.$ and/or documented oxygen therapy) and severe hypoxia $\left(\mathrm{SaO}_{2}<90 \%\right.$ and/or $\mathrm{SaO}_{2}<92 \%$ despite documented oxygen therapy), and defined a 'risk factor for infection' as a documented history of any condition known to increase a child's risk of invasive bacterial infection. Developmental delay was included separately as a potential risk factor, since several studies have documented an increased rate and severity of acute illness including infection among this group. ${ }^{17} 18$ Other definitions reflected those commonly used in clinical practice (table 1); data collected routinely on all children included level of consciousness, capillary refill time, hydration status, and presence and type of rash.

SBI was defined a priori as admission to hospital plus any of the following (in the absence of an alternative non-infective or non-bacterial diagnosis to explain the clinical and laboratory findings): positive bacterial cultures from blood or another normally sterile site in the appropriate clinical context, radiological signs of pneumonia, clinical meningitis plus a cerebrospinal fluid polymorphonuclear leukocytosis, acute febrile purpura, deep collection(s) requiring intravenous antibiotics \pm surgical drainage, a white blood cell count $\geq 20 \times 10^{9} / 1$, a C reactive protein $\geq 120 \mathrm{mg} / 1$, or a final diagnosis of septic arthritis, osteomyelitis, empyema or mastoiditis.

\section{Statistical methods}

Analyses were performed using Stata v 10 (StataCorp LP). The distribution of each variable was summarised with respect to SBI, and crude OR derived. The sensitivity, specificity, positive and negative predictive values (PPV, NPV) and positive and negative likelihood ratios (LR+, LR-) were reported for each variable.
We randomly assigned each child to either a 'derivation' or a 'validation' dataset, such that $\sim 85 \%$ of children were in the derivation set. Multivariate logistic regression models were then derived using the derivation set to develop a clinical prediction score for SBI. We included in the model only variables with at least a weak association with SBI in the univariate analysis (likelihood ratio test (LRT) p value $\leq 0.1$ ), first confining this to categorical variables (which are more easily applied in clinical practice), and then repeating the analysis using the available continuous data to explore to what extent this improved the model.

Backwards stepwise logistic regression was performed first using 'standard' selection criteria, such that variables not significantly associated with SBI (Wald $\mathrm{p}$ value $<0.5$; t test $\mathrm{p}$ value $\leq 0.1$ for continuous variables) are sequentially dropped from the model, and then using 'sign OK' selection, ${ }^{19}$ whereby variables are eliminated from the model only if the sign (+ or -) of the regression coefficient $(\beta)$ is discordant with known or expected clinical associations (since standard selection criteria may not be optimal in the analysis of smaller datasets $\left.{ }^{15}{ }^{19-21}\right)$.

Each model took the form: $S B I=\alpha+\beta_{1} X_{1}+\beta_{2} X_{2}+\beta_{3} X_{3}+\ldots$ $+\beta_{\mathrm{i}} \mathrm{X}_{\mathrm{i}}$, where $\alpha$ is a constant, $\beta_{\mathrm{i}}$ are the regression coefficients for each variable $\left(\mathrm{X}_{\mathrm{i}}\right)$ in the model, and $\mathrm{X}_{\mathrm{i}}$ are coded as 0 or 1 (for binary variables), integers (for ordered categorical variables) or continuous numbers (for continuous variables). For each model we generated a score for each child, such that the score $=\beta_{1} X_{1}+\beta_{2} X_{2}+\beta_{3} X_{3}+\ldots+\beta_{i} X_{i}$. The ability of each score to discriminate children with SBI was quantified in the derivation dataset, and validated in the validation dataset, by calculating the area under the receiver operator characteristics (ROC) curve (AUC) of score as a predictor of SBI.

Finally, the best model was selected to derive a simpler score for clinical use. Criteria for model selection included both discriminant ability (defined by the AUC) and model simplicity. We generated a simplified clinical prediction score using weightings defined by the $\beta$ coefficients of the chosen model, multiplied if necessary by a constant, and rounded as far as possible to the nearest integer. The discriminant ability of this final 'SBI score' was tested by plotting an ROC curve of the score as a predictor of SBI in the entire dataset (derivation and validation sets combined). Risks of SBI were presented stratified by score.

\section{Ethics approval}

Ethics approval was granted by the Nottingham Research Ethics Committee and the ethics committee of the London School of Hygiene and Tropical Medicine.

\section{RESULTS}

There were 2341 eligible children, of whom 17 were excluded because insufficient data were available to confidently determine outcome. A further 373 children were excluded because their date of birth and therefore their age could not be positively determined from the hospital records due to uncertainty in interpreting their handwritten unique patient identifier number on the proforma; the proportion of children with SBI did not differ significantly between those for whom age data were and were not available $(\mathrm{p}=0.47)$.

The final analysis therefore included 1951 children. Their median age was 19 months (range 1 month to 15 years) and $55.4 \%$ were boys. Five hundred and forty-six (28.0\%) children were admitted at first presentation, of whom 72 had SBI. Thirty-six children re-attended hospital within a week 
Table 1 Univariable associations between clinical variables and risk of serious bacterial infection (SBI) in children presenting to the emergency department

\begin{tabular}{|c|c|c|c|c|c|c|}
\hline Clinical variable & & $\mathbf{N}^{*}$ & SBI, n (\%) & OR & $95 \% \mathrm{CI}$ & p Value \\
\hline \multirow[t]{4}{*}{ Age group } & Infants (1-11 months) & 701 & $26(3.7)$ & 1.35 & 0.31 to 5.81 & 0.784 \\
\hline & Preschool (12-59 months) & 855 & $31(3.6)$ & 1.32 & 0.31 to 5.62 & \\
\hline & School age (5-11 years) & 323 & $15(4.6)$ & 1.70 & 0.38 to 7.65 & \\
\hline & Adolescents (12-15 years) & 72 & $2(2.8)$ & 1.00 & - & \\
\hline \multirow[t]{2}{*}{ Sex } & Male & 1081 & $39(3.6)$ & 1.00 & - & 0.562 \\
\hline & Female & 850 & $35(4.1)$ & 1.15 & 0.72 to 1.83 & \\
\hline \multirow[t]{2}{*}{ Risk factor for infection ${ }^{\dagger}$} & No & 1898 & $66(3.5)$ & 1.00 & - & $<0.0001$ \\
\hline & Yes & 53 & $8(15.1)$ & 4.93 & 2.23 to 10.9 & \\
\hline \multirow[t]{2}{*}{ Developmental delay } & No & 1923 & $70(3.6)$ & 1.00 & - & 0.003 \\
\hline & Yes & 28 & $4(14.3)$ & 4.41 & 1.49 to 13.1 & \\
\hline \multirow[t]{4}{*}{ Consciousness level (AVPU score) } & Alert & 1913 & $70(3.7)$ & 1.00 & - & 0.027 \\
\hline & Responds to voice & 18 & $0(0.0)$ & 0.00 & - & \\
\hline & Responds to pain & 5 & $2(40.0)$ & 17.6 & 2.86 to 107.7 & \\
\hline & Unresponsive & 1 & $0(0.0)$ & 0.00 & - & \\
\hline \multirow[t]{3}{*}{ State variation } & Awake & 1909 & $68(3.6)$ & 1.00 & - & $<0.0001$ \\
\hline & Eyes close briefly & 31 & $6(19.4)$ & 6.50 & 2.57 to 16.4 & \\
\hline & Falls asleep & 1 & $0(0.0)$ & 0.00 & - & \\
\hline \multirow[t]{4}{*}{ Temperature $^{\ddagger}$} & $35.0-36.4^{\circ} \mathrm{C}$ & 426 & $9(2.1)$ & 0.82 & 0.37 to 1.82 & $<0.0001$ \\
\hline & $36.5-37.5^{\circ} \mathrm{C}$ & 780 & $20(2.6)$ & 1.00 & - & \\
\hline & $37.5-38.4^{\circ} \mathrm{C}$ & 205 & $17(4.4)$ & 1.86 & 1.01 to 3.43 & \\
\hline & $\geq 38.5^{\circ} \mathrm{C}$ & 305 & $28(9.2)$ & 4.10 & 2.39 to 7.05 & \\
\hline \multirow[t]{2}{*}{ Tachycardia } & Not tachycardic & 974 & $22(2.3)$ & 1.00 & - & 0.0001 \\
\hline & Tachycardic & 651 & $39(6.0)$ & 2.76 & 1.61 to 4.71 & \\
\hline \multirow[t]{2}{*}{ Capillary refill time } & $<2 \mathrm{~s}$ & 1755 & $65(3.7)$ & 1.00 & - & $<0.0001$ \\
\hline & $\geq 2 \mathrm{~s}$ & 40 & 7 (17.5) & 5.52 & 2.34 to 13.0 & \\
\hline \multirow[t]{3}{*}{ Hydration status } & Well hydrated & 1834 & $58(3.2)$ & 1.00 & - & $<0.0001$ \\
\hline & Dry mucous membranes & 102 & $12(11.8)$ & 4.08 & 2.11 to 7.90 & \\
\hline & Reduced skin turgor & 9 & $4(44.4)$ & 24.5 & 6.30 to 95.3 & \\
\hline \multirow[t]{2}{*}{ Hypotension ${ }^{\S}$} & Not hypotensive & 1947 & $74(3.8)$ & 1.00 & - & 0.691 \\
\hline & Hypotensive & 4 & $0(0.0)$ & 0.00 & - & \\
\hline \multirow[t]{2}{*}{ Tachypnoea } & Not tachypnoeic & 656 & $19(2.9)$ & 1.00 & - & 0.028 \\
\hline & Tachypnoeic & 932 & $48(5.2)$ & 1.82 & 1.06 to 3.13 & \\
\hline \multirow[t]{3}{*}{ Hypoxia } & Not hypoxic & 1620 & $49(3.0)$ & 1.00 & - & $<0.0001$ \\
\hline & Mild hypoxia & 265 & $16(6.0)$ & 2.06 & 1.15 to 3.68 & \\
\hline & Severe hypoxia & 66 & $9(13.6)$ & 5.06 & 2.36 to 10.9 & \\
\hline \multirow[t]{2}{*}{ Purpuric rash } & None & 1666 & $66(4.0)$ & 1.00 & - & 0.641 \\
\hline & Purpuric rash & 16 & $1(6.3)$ & 1.62 & 0.21 to 12.4 & \\
\hline \multirow[t]{2}{*}{ Petechial rash } & None & 1666 & $66(4.0)$ & 1.00 & - & 0.793 \\
\hline & Petechial rash & 42 & 2 (4.8) & 1.21 & 0.29 to 5.13 & \\
\hline \multirow[t]{2}{*}{ Macular rash } & None & 1757 & $70(4.0)$ & 1.00 & - & 0.184 \\
\hline & Macular rash & 194 & $4(2.1)$ & 0.51 & 0.18 to 1.41 & \\
\hline
\end{tabular}

${ }^{*} \mathrm{~N}$ indicates the total number children in a particular category. Note that the sum of $\mathrm{N}$ across all categories of a particular variable is equal to the total number of children for which data were available for that variable. For most variables this is less than the total number of children (1032) included in the analysis due to missing data for that particular variable.

†Identified risk factors for bacterial infection in this analysis included neutropaenia, sickle cell disease, primary ciliary dyskinesia, Down's syndrome, glycogen storage disease $1 \mathrm{~b}$, Hunter's syndrome, Hurler's syndrome, cryptogenic cirrhosis, biliary atresia, vesico-ureteric reflux, hydronephrosis, congenital pneumonia and a documented history of recurrent bacterial infections.

期mperature categories $35.0-36.4^{\circ} \mathrm{C}$ and $36.5-37.5^{\circ} \mathrm{C}$ were combined in the multivariate analysis to allow temperature to be modelled as a linear variable. No children had a temperature $<35.0^{\circ} \mathrm{C}$ in this study.

${ }^{\S}$ Blood pressure recordings were only available for 94 children; the remaining children were classified as not hypotensive for the purposes of the analysis.

of their initial presentation and within the same illness episode, 18 of whom were admitted and 2 of whom had SBI. The principal final diagnoses of the 74 (3.8\%) children with SBI included pneumonia (52), sepsis without a clear focus (14), soft tissue infections (5), urinary sepsis (2) and tonsillitis plus sepsis (1).

Several clinical variables were strongly associated with SBI in the univariate analysis (table 1), including signs of a child's a neurologic, haemodynamic and respiratory state, and a known risk factor for infection. Although hypotension was not significantly associated with SBI, it is important to note that blood pressure data were only available for 103 (5.3\%) children.

The predictive values of each variable are summarised in table 2. Apart from tachypnoea (sensitivity $71.6 \%$ ), the sensitivity of most clinical signs was poor. However, some clinical signs, such as those of reduced level of consciousness/alertness and impaired perfusion were highly specific, and demonstrated more clinically useful positive likelihood ratios. The low prior probability of SBI in this population explains the apparently 
Table 2 Predictive value of clinical variables for serious bacterial infection

\begin{tabular}{|c|c|c|c|c|c|c|}
\hline Clinical variable & Sensitivity, \% (95\% Cl) & Specificity, \% (95\% Cl) & PPV, \% (95\% Cl) & NPV, \% (95\% Cl) & $\mathrm{LR}+(95 \% \mathrm{CI})$ & LR- $(95 \%$ CI $)$ \\
\hline Risk factor for infection & 10.8 (4.8 to 20.2 ) & 97.6 (96.8 to 98.2 ) & 15.1 (6.7 to 28.0 ) & 96.5 (95.6 to 97.3 ) & 4.5 (3.3 to 6.2 ) & 0.91 (0.67 to 1.25 ) \\
\hline Developmental delay & 5.4 (1.5 to 13.3$)$ & 98.7 (98.1 to 99.2 ) & 14.3 (4.0 to 32.7$)$ & 96.4 (95.4 to 97.2 ) & 4.2 (4.2 to 4.3 ) & 0.96 (0.95 to 0.97$)$ \\
\hline \multicolumn{7}{|l|}{ Consciousness level } \\
\hline No response to voice & $2.8(0.34$ to 9.7$)$ & 99.8 (99.5 to 99.9 ) & 33.3 (4.3 to 77.7$)$ & 96.4 (95.4 to 97.2 ) & $13.0(9.2$ to 18.2$)$ & 0.97 (0.69 to 1.4$)$ \\
\hline Unresponsive & $0.0(0.0$ to 5.0$) \dagger$ & $99.9(99.7$ to 100.0$)$ & $0.0(0.0$ to 97.5$) \dagger$ & 96.1 (95.2 to 97.0$)$ & 0.0 & 1.0 \\
\hline Falls asleep & $0.0(0.0$ to 4.9$) \dagger$ & 99.9 (99.7 to 100.0$)$ & $0.0(0.0$ to 97.5$) \dagger$ & $96.2(95.2$ to 97.0$)$ & 0.0 & 1.0 \\
\hline \multicolumn{7}{|l|}{ Temperature } \\
\hline$\geq 37.5^{\circ} \mathrm{C}$ & 60.8 (48.8 to 72.0$)$ & 64.5 (62.2 to 66.7$)$ & 6.5 (4.8 to 8.6$)$ & 2.4 (1.6 to 3.4$)$ & $1.7(0.65$ to 4.5$)$ & 0.61 (0.23 to 1.61$)$ \\
\hline$\geq 38.5^{\circ} \mathrm{C}$ & 37.8 (26.8 to 49.9$)$ & 84.8 (83.1 to 86.4 ) & $9.2(6.2$ to 13.0$)$ & 97.1 (96.1 to 97.9$)$ & 2.5 (1.1 to 5.7$)$ & 0.73 (0.32 to 1.7$)$ \\
\hline Tachycardia & 63.9 (50.6 to 75.8$)$ & $60.9(58.4$ to 63.3$)$ & $6.0(4.3$ to 8.1$)$ & 97.7 (96.6 to 98.6$)$ & $1.6(0.67$ to 4.0$)$ & $0.59(0.24$ to 1.5$)$ \\
\hline Capillary refill time $\geq 2 \mathrm{~s}$ & 9.7 (4.0 to 19.0$)$ & 98.1 (97.3 to 98.7$)$ & 17.5 (7.3 to 32.8$)$ & 96.3 (95.3 to 97.1$)$ & $5.1(4.0$ to 6.5$)$ & $0.92(0.72$ to 1.2$)$ \\
\hline Tachypnoea & 71.6 (59.3 to 82.0) & 41.9 (39.4 to 44.4$)$ & 5.2 (3.8 to 6.8 ) & 97.1 (95.5 to 98.2) & $1.2(0.47$ to 3.2$)$ & 0.68 (0.26 to 1.8$)$ \\
\hline \multicolumn{7}{|l|}{ Hypoxia } \\
\hline Mild or severe & $33.8(23.2$ to 45.7$)$ & 83.7 (81.9 to 85.3 ) & 7.6 (4.9 to 10.9$)$ & 97.0 (96.0 to 97.8 ) & 2.1 (0.95 to 4.5$)$ & $0.79(0.36$ to 1.7$)$ \\
\hline Severe & 12.2 (5.7 to 21.8$)$ & $97.0(96.1$ to 97.7$)$ & $13.6(6.4$ to 24.3$)$ & 966 (95.6 to 97.3 ) & $4.0(2.8$ to 5.8$)$ & $0.91(0.63$ to 1.3$)$ \\
\hline \multicolumn{7}{|l|}{ Rash } \\
\hline Purpuric rash & $1.5(0.04$ to 8.0$)$ & 99.1 (98.5 to 99.5$)$ & $6.3(0.2$ to 30.2$)$ & 96.0 (95.0 to 96.9$)$ & 1.6 (0.8 to 3.2 ) & $0.99(0.50$ to 2.0$)$ \\
\hline Petechial rash & $2.9(0.4$ to 10.2$)$ & 97.6 (96.7 to 98.3$)$ & $4.8(0.6$ to 16.2$)$ & $96.0(95.0$ to 96.9$)$ & $1.1(0.79$ to 1.6$)$ & $1.0(0.71$ to 1.4$)$ \\
\hline Macular rash & $5.4(1.5$ to 13.3$)$ & 89.9 (88.4 to 91.2 ) & 2.1 (0.6 to 5.2 ) & $96.0(95.0$ to 96.9$)$ & 0.53 (0.53 to 0.54$)$ & 1.1 (1.0 to 1.1$)$ \\
\hline
\end{tabular}

${ }^{*}$ Not alert indicates only responds to voice or pain, or unresponsive.

${ }^{\dagger}$ One sided, $97.5 \% \mathrm{Cl}$.

$\mathrm{LR}+$, likelihood ratio of a positive test; LR-, likelihood ratio of a negative test; NPV, predictive value of a negative test; PPV, predictive value of a positive test.

Table 3 Regression coefficients $(\beta)$, and adjusted $\mathrm{OR}$ and $95 \% \mathrm{Cl}$ for variables included in the chosen model

\begin{tabular}{llclr}
\hline Variables & $\beta$ Coefficient & OR & 95\% Cl & p Value \\
\hline History of developmental delay & 1.6807 & 5.4 & 1.6 to 18.6 & 0.008 \\
Risk factor for infection & 1.4408 & 4.2 & 0.9 to 20.9 & 0.077 \\
State variation & 0.2336 & 1.3 & 0.3 to 4.7 & 0.728 \\
Temperature category & 0.6643 & 1.9 & 1.4 to 2.7 & $<0.001$ \\
Capillary refill time & 0.6595 & 1.9 & 0.6 to 5.8 & 0.243 \\
Dehydration category & 1.3651 & 39 & 2.0 to 7.6 & $<0.001$ \\
Tachypnoea & 0.1760 & 1.2 & 0.6 to 2.2 & 0.585 \\
Hypoxia category & 0.4734 & 1.6 & 1.1 to 2.4 & 0.026 \\
\hline
\end{tabular}

high negative predictive values of many variables, reflected in the poor utility of most negative likelihood ratios.

After random weighted allocation of children to the derivation and validation sets, the derivation set comprised 1600 $(85.2 \%)$ children without SBI and 64 (86.5\%) children with SBI. The models with the best discriminative ability were those derived using 'sign $\mathrm{OK}^{\mathrm{\prime}}$ ' selection. For the 'sign $\mathrm{OK}^{\prime}$ model confined to categorical variables, the AUCs in the derivation and validation sets were $0.76(0.68$ to 0.82$)$ and 0.85 (0.71 to 0.99$)$, respectively. Inclusion of continuous data in the model did not markedly improve performance (AUC 0.76 and 0.86 in the derivation and validation sets, respectively), so the simpler model confined to categorical variables was selected. Regression coefficients and adjusted ORs and 95\% CIs for each variable included in this model are given in table 3. A modified SBI score was derived based on the $\beta$ coefficients of this model, such that:
The AUC for SBI score as a predictor of SBI in the derivation and validation sets combined was 0.77 (95\% CI 0.71 to 0.83 ; figure 1). Table 4 shows the SBI score in tabular form more conveniently for clinical use, and risks of SBI stratified by SBI score are shown in table 5.

\section{DISCUSSION}

By exploring the feasibility of developing a clinical prediction score for risk stratification of suspected serious bacterial illness in children, this study addresses an important challenge in everyday clinical practice in the UK and other developed countries. ${ }^{1257}$ Among children presenting to emergency care in whom infection was suspected (where the prior probability of SBI was $5 \%$ ), our SBI score was able to rule out SBI with reasonable confidence and precision in three quarters of children in the dataset to whom the score was applied (SBI score $\leq 5$ associated with $<2 \%$ risk of $\mathrm{SBI}$ ), to identify children at the highest risk of SBI (a third of children with an SBI score $>8$ had $\mathrm{SBI}$ ) and to risk stratify the remaining children into groups with increasing risk.

We modelled continuous data as categorical and continuous variables in separate models. Although less suitable for the development of a clinical prediction score for clinicians, continuous variables maximise information ${ }^{15} 22$ and can be utilised in computer-assisted diagnostic pathways. However, their inclusion in the model did not improve discriminative ability sufficiently to justify the increased complexity.

Previous studies in developed countries have attempted to derive clinical scores as a tool to identify seriously ill children at presentation. ${ }^{23-35}$ Most were carried out in populations with a higher incidence of SBI prior to the introduction of 


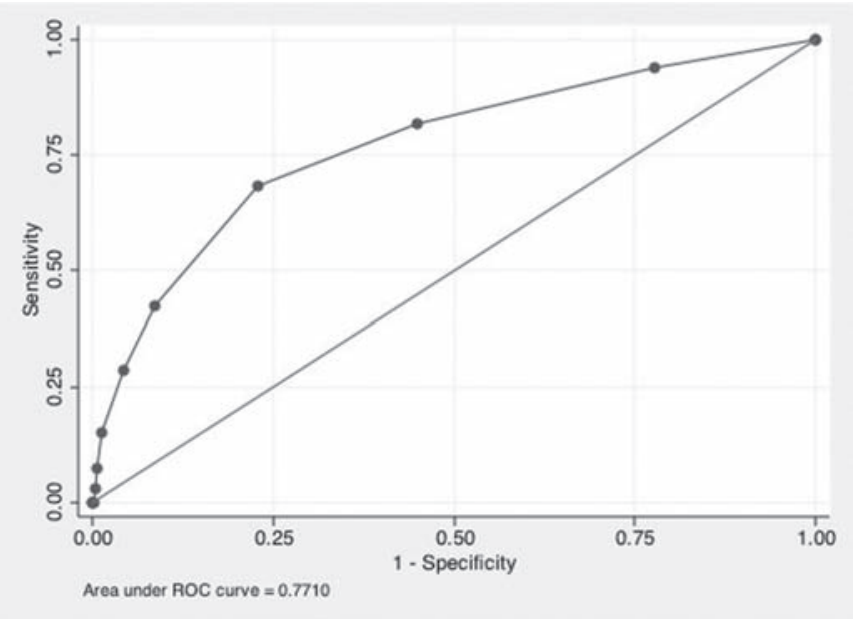

Figure 1 Receiver operator characteristics (ROC) curve of serious bacterial infection score as a predictor of serious bacterial infection in the entire dataset.

routine vaccination against Haemophilus influenza type $b(\mathrm{Hib})$ and Streptococcus pneumoniae; others were designed to predict the need for admission to intensive care. ${ }^{9}$ Moreover, promising initial reports of diagnostic performance have not always been consistently reproducible. ${ }^{27} 3637$ This probably reflects a combination of the inherent over-optimism of data-driven model predictions based on small datasets, $15192138-40$ failure to validate models and/or scores in an independent dataset, 1519 and spectrum bias arising from the use of case-control designs. ${ }^{41-43}$ In a recent study based mainly in primary care, a clinical algorithm was derived with the ability to rule out SBI with reasonable confidence. ${ }^{44}$ However, these results have not been validated in an independent dataset, and negative predictive values are likely to be lower in emergency department settings where the prior probability of SBI is higher.

The strengths of our study include the large number of children studied, detailed review of all clinical and laboratory data to assign outcome, validation of the model in an independent part of the dataset, and inclusion of all children presenting with suspected SBI in a cohort study design, which suggests the predictive value of our SBI score should be generalisable to other similar settings. Furthermore, focusing on children with suspected SBI rather than all children with serious illness allowed inclusion of clinical risk factors specific to infection, and may have helped improve model specificity. It is important to stress that while the SBI score should be generalisable to emergency departments in the developed world, it is unlikely to be applicable to developing world settings where the prevalence of SBI among paediatric presentations is much higher and there may be other important risk factors for infection such as malnutrition and HIV. ${ }^{5}$

A potential limitation of the study concerns the definition of SBI. No single, reliable gold standard exists for the diagnosis of invasive bacterial infections in children. Although cultures from blood and other sterile sites are highly specific, sensitivity is limited. ${ }^{45-47}$ The definition of SBI used has been formulated to take account of all available clinical and laboratory information in defining each clinical syndrome, including a child's response to treatment, and is designed to capture all children with invasive or otherwise SBIs who require admission to hospital. A potential criticism is the risk of incorporation bias, since clinicians are not blind to the admission
Table 4 Serious bacterial infection (SBI) score for prediction of serious bacterial infection

\begin{tabular}{lll}
\hline Clinical variable & & Score $^{*}$ \\
\hline Developmental delay & No delay & 0 \\
& Delay & 4 \\
Risk factor for infection & No risk factor & 0 \\
& Risk factor present & 2 \\
State variation & Eyes open & 0 \\
& Eyes close briefly & 1 \\
Temperature & Falls asleep & 2 \\
& $<37.5^{\circ} \mathrm{C}$ & 0 \\
Capillary refill time (s) & $37.5-38.4^{\circ} \mathrm{C}$ & 1 \\
& $\geq 38.5^{\circ} \mathrm{C}$ & 2 \\
Hydration status & $<2$ & 0 \\
& $\geq 2$ & 1 \\
Respiratory rate & Well hydrated & 0 \\
Hypoxia & Dry mucous membranes & 2 \\
& Reduced skin turgor & 4 \\
& Not tachypnoeic & 0 \\
& Tachypnoeic & 1 \\
& Not hypoxic & 0 \\
& Mild hypoxia & 1 \\
& Severe hypoxia & 2
\end{tabular}

${ }^{*}$ Score indicates the sum of scores for each clinical variable (maximum score 18). Table 5 shows risks of serious bacterial infection stratified by SBI score.

clinical variables studied, which are likely to influence admission decisions; inclusion of clinical and laboratory data from the entire admission in assigning outcome is likely to only partly mitigate this bias. Nevertheless, we believe the definition adopted represents a pragmatic working definition of SBI. Importantly, we were also able to identify those children discharged from hospital who re-attended within a week, and to amend their SBI classification as required. While we cannot exclude the possibility that other children may have re-presented elsewhere, the nearest emergency department, which does not have a dedicated paediatric section, is 18 miles away, so the chance of this is small. Similarly, since sudden childhood death is rare in this population and most cases are brought to hospital, the chance of a child in this study dying at home and not re-attending hospital is also small.

Missing data also limit the power of our analysis. Although the proportion of data missing for individual variables was generally small, this became more significant in the multivariate analysis. Blood pressure is not routinely measured in paediatric clinical practice except in the sickest children, so data were missing for most patients. Nevertheless, blood pressure may have an important role in predicting SBI that this analysis would not be able to identify. The number of children for whom age data were missing is unfortunate as it further limits study power; however, this is unlikely to have introduced any bias since the underlying problem (poor legibility of the proforma) is unlikely to be related to the clinical presentation and was not associated with SBI.

Finally, measurement error is also possible, since emergency department staff assessed each clinical sign using routine clinical tools. For some variables this is likely to be minimal since automated measurements were used. Arguably, even for other variables this may be seen as a strength of the study, since it increases its generalisability to the routine clinical setting.

The implications of this study for clinical practice are threefold. First, the specificity of some clinical signs for SBI (such 
Table 5 Risks of significant bacterial infection (SBI) stratified by SBI score

\begin{tabular}{lclc}
\hline SBI score & Children (N) & Children with SBI (n) & Risk of SBI, \% (95\% Cl) \\
\hline$\leq 5$ & 1085 & 21 & $1.9(1.2$ to 2.9$)$ \\
6 & 214 & 17 & $7.9(4.7$ to 12.4$)$ \\
7 & 68 & 9 & $13.2(6.2$ to 23.6$)$ \\
8 & 51 & 9 & $17.7(8.4$ to 30.9$)$ \\
$>8$ & 29 & 10 & $34.5(17.9$ to 54.3$)$ \\
Total $^{*}$ & 1447 & 66 & $4.6(3.5$ to 5.8$)$ \\
\hline
\end{tabular}

*Total represents the total number of children in the entire dataset (derivation and validation sets combined) for whom data on all clinical variables included in the final model were available.

as reduced activity or level of consciousness, prolonged capillary refill time and reduced skin turgor) support the National Institute for Health and Clinical Excellence clinical guidelines ${ }^{7}$ which use these clinical features as 'red flags' to identify seriously ill children. The presence of these features in a febrile child should prompt a careful clinical assessment. Second, it clearly demonstrates the potential utility of a clinical score to stratify children according to their risk of SBI. Such a score might be incorporated into electronic decision support and medical records. Finally, it underlines the need to use such a clinical score as part of a broader algorithm to guide management decisions (including additional investigations, plans for review or admission for observation) to further stratify a child's risk. Future research should explore the benefit of including in the model other risk factors such as immunisation status, routine blood pressure measurement, and other potential markers of sepsis such as limb pain or cool peripheries, ${ }^{2}$ investigate how laboratory tests such as C-reactive protein, procalcitonin and white blood cell count may best be incorporated into a clinical algorithm to refine a child's risk status, and further validate the performance and impact ${ }^{14} 48$ of the score in different acute paediatric settings, including primary care.

Contributors $A J B$ and $M L$ are joint first authors.

Acknowledgements The authors would like to thank Dr Terence Stephenson for his contributions to the initial data collection.

The study was carried out on behalf of the Royal College of Paediatrics and Child Health (RCPCH) working group on Recognising Acute Illness in Children (RAIC). MT is a member of University of Oxford Department of Primary Health Care which is part of the NIHR National School of Primary Care Research. ML is a member of the Leicester Collaboration for Leadership in Applied Health Research and Care (CLARCH) team and Director of the Health Education Research and Development Unit (HERADU).

Funding AJB is supported by a Wellcome Trust research training fellowship (081697). The authors wish to thank the Well Child Medical Charity for their funding of the studies in Nottingham and of this study.

\section{Competing interests None.}

Ethics approval This study was conducted with the approval of the Nottingham Research Ethics Committee and the ethics committee of the London School of Hygiene and Tropical Medicine.

Provenance and peer review Not commissioned; externally peer reviewed.

\section{REFERENCES}

1. Pearson GAE. Why Children Die: A Pilot Study 2006; England (South West, North East and West Midlands), Wales and Northern Ireland. London: Confidential Enquiry into Maternal and Child Health, 2008.

2. Thompson MJ, Ninis N, Perera R, et al. Clinical recognition of meningococcal disease in children and adolescents. Lancet 2006;367:397-403.

3. Kumar A, Roberts D, Wood KE, et al. Duration of hypotension before initiation of effective antimicrobial therapy is the critical determinant of survival in human septic shock. Crit Care Med 2006;34:1589-96.

4. Dellinger RP, Levy MM, Carlet JM, et al. Surviving Sepsis Campaign: international guidelines for management of severe sepsis and septic shock: 2008 Crit Care Med 2008:36:296-327.
5. Van den Bruel A, Haj-Hassan T, Thompson M, et al. Diagnostic value of clinical features at presentation to identify serious infection in children in developed countries: a systematic review. Lancet 2010;375:834-45.

6. Tasche M, Oosterberg E, Kolnaar B, et al. Inventory of gaps in the evidence base of general practice. Huisarts Wet 2001;44:91-4.

7. National Institute for Health and Clinical Excellence. Feverish Illness in Children: Assessment and Initial Management in Children Younger Than 5 Years. London: NICE, 2007.

8. Antman EM, Cohen M, Bernink PJ, et al. The TIMI risk score for unstable angina/ non-ST elevation MI: A method for prognostication and therapeutic decision making. JAMA 2000;284:835-42.

9. Duncan H, Hutchison J, Parshuram CS. The Pediatric Early Warning System score: a severity of illness score to predict urgent medical need in hospitalized children. J Crit Care 2006;21:271-8.

10. Haines C, Perrott M, Weir P. Promoting care for acutely ill children-development and evaluation of a paediatric early warning tool. Intensive Crit Care Nurs 2006;22:73-81.

11. Mwachari C, Nduba V, Nguti R, et al. Validation of a new clinical scoring system for acute bronchitis. Int J Tuberc Lung Dis 2007;11:1253-9.

12. van Koningsveld R, Steyerberg EW, Hughes RA, et al. A clinical prognostic scoring system for Guillain-Barré syndrome. Lancet Neurol 2007;6:589-94.

13. Wells PS, Anderson DR, Rodger $\mathrm{M}$, et al. Derivation of a simple clinical model to categorize patients probability of pulmonary embolism: increasing the models utility with the SimpliRED D-dimer. Thromb Haemost 2000;83:416-20.

14. Moons KG, Royston P, Vergouwe $Y$, et al. Prognosis and prognostic research: what, why, and how? BMJ 2009;338:b375.

15. Royston P, Moons KG, Altman DG, et al. Prognosis and prognostic research: Developing a prognostic model. BMJ 2009;338:b604.

16. Advanced Life Support Group. Advanced Paediatric Life Support: The Practical Approach. Fourth edition. Wiley-Blackwell, Oxford, UK: 2004.

17. Graham RJ. Specialty services for children with special health care needs: supplement not supplant the medical home. Arch Dis Child 2008;93:2-4.

18. Mahon M, Kibirige MS. Patterns of admissions for children with special needs to the paediatric assessment unit. Arch Dis Child 2004;89:165-9.

19. Steyerberg EW, Eijkemans MJ, Harrell FE Jr, et al. Prognostic modeling with logistic regression analysis: in search of a sensible strategy in small data sets. Med Decis Making 2001;21:45-56.

20. Sun GW, Shook TL, Kay GL. Inappropriate use of bivariable analysis to screen risk factors for use in multivariable analysis. J Clin Epidemiol 1996;49:907-16.

21. Harrell FE Jr, Lee KL, Mark DB. Multivariable prognostic models: issues in developing models, evaluating assumptions and adequacy, and measuring and reducing errors. Stat Med 1996;15:361-87.

22. Altman DG, Royston P. The cost of dichotomising continuous variables. BMJ 2006;332:1080.

23. Egdell P, Finlay L, Pedley DK. The PAWS score: validation of an early warning scoring system for the initial assessment of children in the emergency department. Emerg Med J 2008;25:745-9.

24. McCarthy PL, Sharpe MR, Spiesel SZ, et al. Observation scales to identify serious illness in febrile children. Pediatrics 1982;70:802-9.

25. McCarthy PL, Jekel JF, Stashwick CA, et al. History and observation variables in assessing febrile children. Pediatrics 1980;65:1090-5.

26. McCarthy PL, Jekel JF, Stashwick CA, et al. Further definition of history and observation variables in assessing febrile children. Pediatrics 1981;67:687-93.

27. Kuppermann N, Fleisher GR, Jaffe DM. Predictors of occult pneumococcal bacteremia in young febrile children. Ann Emerg Med 1998;31:679-87.

28. Nelson KG. An index of severity for acute pediatric illness. Am J Public Health 1980; $70: 804-7$.

29. Bass JW, Steele RW, Wittler RR, et al. Antimicrobial treatment of occult bacteremia: a multicenter cooperative study. Pediatr Infect Dis J 1993;12:466-73.

30. Dershewitz RA, Wigder HN, Wigder CM, et al. A comparative study of the prevalence, outcome, and prediction of bacteremia in children. $J$ Pediatr 1983;103:352-8.

31. McCarthy PL, Lembo RM, Baron MA, et al. Predictive value of abnormal physical examination findings in ill-appearing and well-appearing febrile children. Pediatrics 1985;76:167-71.

32. McCarthy PL, Lembo RM, Fink HD, et al. Observation, history, and physical examination in diagnosis of serious illnesses in febrile children less than or equal to 24 months. J Pediatr 1987;110:26-30.

33. Schwartz RH, Wientzen RL Jr. Occult bacteremia in toxic-appearing, febrile infants. A prospective clinical study in an office setting. Clin Pediatr (Phila) 1982;21:659-63.

34. Waskerwitz S, Berkelhamer JE. Outpatient bacteremia: clinical findings in children under two years with initial temperatures of 39.5 degrees $C$ or higher. J Pediatr 1981;99:231-3.

35. Yilmaz HL, Yildizdas RD, Alparslan N, et al. Screening tools for bacteraemia in a selected population of febrile children. Ann Acad Med Singap 2008;37:192-9.

36. Baker MD, Avner JR, Bell LM. Failure of infant observation scales in detecting serious illness in febrile, 4- to 8-week-old infants. Pediatrics 1990;85:1040-3. 
37. Teach SJ, Fleisher GR. Efficacy of an observation scale in detecting bacteremia in febrile children three to thirty-six months of age, treated as outpatients. Occult Bacteremia Study Group. J Pediatr 1995;126:877-81.

38. Efron B. Estimating the error rate of a prediction rule: improvement on crossvalidation. J Am Stat Assoc 1986;78:316-31.

39. Laupacis A, Sekar N, Stiell IG. Clinical prediction rules. A review and suggested modifications of methodological standards. JAMA 1997;277:488-94.

40. Peduzzi $\mathbf{P}$, Concato J, Kemper $\mathbf{E}$, et al. A simulation study of the number of events per variable in logistic regression analysis. J Clin Epidemiol 1996:49:1373-9.

41. Banoo S, Bell D, Bossuyt $P$, et al. Evaluation of diagnostic tests for infectious diseases: general principles. Nat Rev Microbio/ 2006:4:S20-32.

42. Lijmer JG, Mol BW, Heisterkamp S, et al. Empirical evidence of design-related bias in studies of diagnostic tests. JAMA 1999;282:1061-6.

43. Ransohoff DF, Feinstein AR. Problems of spectrum and bias in evaluating the efficacy of diagnostic tests. N Eng/ J Med 1978;299:926-30.
44. Van den Bruel A, Aertgeerts B, Bruyninckx R, et al. Signs and symptoms for diagnosis of serious infections in children: a prospective study in primary care. Br J Gen Pract 2007:57:538-46.

45. Cutts FT, Zaman SM, Enwere G, et al. Efficacy of nine-valent pneumococcal conjugate vaccine against pneumonia and invasive pneumococcal disease in The Gambia: randomised, double-blind, placebo-controlled trial. Lancet 2005;365:1139-46.

46. Sáez-Llorens X, Vargas S, Guerra F, et al. Application of new sepsis definitions to evaluate outcome of pediatric patients with severe systemic infections. Pediatr Infect Dis J 1995;14:557-61.

47. Luck S, Torny M, d'Agapeyeff K, et al. Estimated early-onset group B streptococcal neonatal disease. Lancet 2003;361:1953-4.

48. Moons KG, Altman DG, Vergouwe Y, et al. Prognosis and prognostic research: application and impact of prognostic models in clinical practice. BMJ 2009;338:b606. 